\title{
A Systematic Literature Review of Practices in Customer Experience Management: An Abstract
}

\author{
Farah Arkadan, Emma K. Macdonald, and Hugh N. Wilson
}

\begin{abstract}
What is the firm's role in influencing their customer's experience? Despite its prominence and popularity in practice, it is unclear what customer experience management (CEM) as an overall business focus means or entails. To establish what is known about CEM and conceptualize a construct for it, we systematically and critically review existing empirical evidence. This study identifies 37 studies that explicitly research CEM within a business-to-consumer (B2C) context and from a firm's point of view. The authors find 26 CEM practices, each falling within three types of CEM: (1) strategizing, (2) operating, and (3) enabling the customer experience. Emerging from our study is the emphasis on studying and designing experience journeys and fostering an experience-centric organizational orientation. Implications for marketing management strategy emphasize the need to focus on experience quality and not just product, channel, or service quality.
\end{abstract}

F. Arkadan $(\bowtie) \bullet$ E.K. Macdonald • H.N. Wilson

Cranfield School of Management, Bedford, UK

e-mail: farah.arkadan@cranfield.ac.uk; emma.macdonald@cranfield.ac.uk;

hugh.wilson@cranfield.ac.uk 